\title{
Curative treatment for esophageal cancer: Vancouver Island Cancer Centre experience from 1993 to 1998
}

\author{
Kenneth S Wilson MD FRCPE FACP FRCPC ${ }^{1,2,3}$, Amanda G Wilson ${ }^{4}$, \\ Gary J Dewar MD FRCSC ${ }^{5}$
}

KS Wilson, AG Wilson, GJ Dewar. Curative treatment for esophageal cancer: Vancouver Island Cancer Centre experience from 1993 to 1998. Can J Gastroenterol 2002;16(6):361-368.

OBJECTIVES: To review outcomes after curative treatment for esophageal cancer in the Vancouver Island Cancer Centre from 1993 to 1998. Curative treatments included esophagectomy alone, and chemoradiotherapy with 'selective surgery' for patients with post-treatment-positive endoscopic biopsy or less than 75\% regression on computed axial tomography scan, or with resectable local recurrence.

METHODS: Patients undergoing esophagectomy alone, or primary chemoradiotherapy and 'selective surgery' were reviewed. This was a retrospective, nonrandomized, institutional experience. Surgical complication, relief of dysphagia, disease-specific survival rates and prognostic factors were analyzed.

RESULTS: Nineteen patients underwent esophagectomy alone. A total of 56 patients underwent primary chemoradiotherapy, of whom 16 had 'selective surgery'. Relief of dysphagia was similar in both groups of esophagectomy patients. Exploration for 'selective surgery' was performed in 12 patients after their first postchemoradiotherapy endoscopy (two patients had unresectable disease), and in seven for relapse, one of whom died intraoperatively.
Overall, the mortality rate due to surgery was 3\%. Chemoradiotherapy was not associated with more frequent serious surgical complications. For patients who underwent esophagectomy alone and those who underwent chemoradiotherapy plus selective surgery, the median survival times were 12.9 and 16.4 months, respectively, and the three-year survival rates were $21 \%$ and $37 \%$, respectively. Seventeen of 25 patients who underwent chemoradiotherapy and who survived more than two years have not required selective surgery. For the two groups of patients combined, no single prognostic factor for survival was significant in multivariate analysis, but for patients who underwent chemoradiotherapy plus selective surgery, negative endoscopic biopsy was highly significant.

CONCLUSIONS: Surgical complication and disease-specific survival rates after primary chemoradiotherapy with selective surgery compare favourably with esophagectomy alone in the curative treatment of esophageal cancer. A prospective, randomized trial is necessary for the definitive evaluation of the strategy of chemoradiotherapy and selective surgery.

Key Words: Chemoradiotherapy; Esophageal cancer; Esophagectomy

Résumé à la page suivante

\footnotetext{
${ }^{1}$ Vancouver Island Cancer Centre; ${ }^{2}$ Department of Medicine, University of British Columbia; ${ }^{3}$ Department of Medicine, Greater Victoria Hospital Society; ${ }^{4}$ University of Victoria; and ${ }^{5}$ Department of Surgery, Greater Victoria Hospital Society, Victoria, British Columbia

Correspondence and reprints: Dr KS Wilson, Vancouver Island Cancer Centre, 2410 Lee Avenue, Victoria, British Columbia V8R 6V5.

Telephone 250-519-5572, fax 250-519-2017, e-mail kwilson@bccancer.bc.ca

Received for publication May 24, 2001. Accepted February 15, 2002
} 


\section{Le traitement curatif du cancer osophagien : L'expérience du Vancouver Island Cancer Centre, de 1993 à 1998}

OBJECTIFS : Examiner l'évolution du traitement curatif du cancer œsophagien au Vancouver Island Cancer Centre entre 1993 et 1998. Les traitements curatifs sont l'œsophagectomie seule et la chimioradiothérapie accompagnée d'une opération sélective pour les patients dont la biopsie endoscopique demeure positive après le traitement, dont la régression est inférieure à $75 \%$ selon la tomodensitométrie ou dont le foyer de récurrence peut être réséqué.

MÉTHODOLOGIE : Les patients qui ont subi une œsophagectomie seule ou une chimioradiothérapie accompagnée d'une opération sélective ont été passés en revue. Il s'agissait d'une rétrospective non aléatoire au sein de l'établissement. La complication chirurgicale, le soulagement de la dysphagie, les taux de survie propres à la maladie et les facteurs pronostiques ont été analysés.

RÉSULTATS : Dix-neuf patients ont subi une œsophagectomie seule. Au total, 56 patients ont subi une chimioradiothérapie primaire suivie, pour 16 d'entre eux, d'une opération sélective. Le soulagement de la dysphagie était similaire dans les deux groupes de patients ayant subi l'œsophagectomie. L'exploration en vue de l'opération sélective a été effectuée chez 12 patients après la première endoscopie suivant la chimioradiothérapie (chez deux patients, la maladie était impossible à réséquer) et chez sept autres après une rechute. L'un d'eux est décédé pendant l'opération. Dans l'ensemble, le taux de mortalité provoqué par la chirurgie s'élevait à $3 \%$. La chimioradiothérapie ne s'associait pas à plus de complications chirurgicales graves. Dans le cas des patients qui n'ont subi que l'œsophagectomie et de ceux qui ont subi une chimioradiothérapie accompagnée d'une opération sélective, la durée de survie moyenne était de 12,9 mois et de 16,4 mois, respectivement, et le taux de survie après trois ans de $21 \%$ et $37 \%$, respectivement. Dix-sept des 25 patients qui ont subi une chimioradiothérapie et survécu plus de deux ans n'ont pas eu besoin de se faire opérer. Chez les deux groupes de patients combinés, aucun facteur pronostique de survie n'avait une importance particulière d'après l'analyse multivariée, mais chez les patients qui ont subi la chimioradiothérapie en plus de la chirurgie sélective, le taux de biopsie endoscopique négative était très significatif.

CONCLUSIONS : Le taux de complications chirurgicales et le taux de survie propre à la maladie après une chimioradiothérapie primaire accompagnée d'une opération sélective se comparent favorablement à ceux de l'œsophagectomie seule dans le traitement curatif du cancer œesophagien. Un essai aléatoire et prospectif s'impose pour parvenir à une évaluation définitive de la stratégie de la chimioradiothérapie et de l'opération sélective.
$\mathrm{T}$ here are two potentially curative modalities for esophageal cancer (1). The core modality is esophagectomy for patients fit for surgery and chemoradiotherapy for those who are unsuitable for surgery. However, only about $50 \%$ of patients referred for esophageal cancer surgery have resectable disease, and the one-, two- and five-year survival rates are $56 \%, 34 \%$ and $11 \%$, respectively (2). There is controversy about whether there is a significant survival benefit for all 'surgical' patients if they receive preoperative chemoradiotherapy (3-5). An Inter-Group study (CLBC9781) is seeking a definitive answer to this question.

Esophagectomy alone carries significant morbidity and mortality risks (6) that may be increased by the addition of preoperative chemoradiotherapy. In one series, a reduction in cancer-related deaths was negated by an increase in the rate of postoperative deaths (3). Clearly, the chosen chemoradiotherapy regimen, in addition to improving pathological complete remission rates and cancer-specific survival, must be acceptable in terms of operative risk.

Primary chemoradiotherapy was introduced at the Vancouver Island Cancer Centre, British Columbia, in 1993 for the treatment of localized esophageal cancer. The chemoradiotherapy protocol, toxicities and rates of survival have been reported $(7,8)$. Distinguishing features were the criteria for esophagectomy (ie, only patients thought to have resectable persistent or recurrent disease after chemoradiotherapy) and that suitability for esophagectomy at diagnosis was not an entry criterion. Because of perceived concerns about the surgical risks of operating sooner or later after chemoradiotherapy, and not operating on all patients with or without chemoradiotherapy, we report our experience using curative treatments for esophageal cancer from 1993 to 1998. The study comprised two nonrandomized groups of patients, one treated with esophagectomy alone, and the other treated with primary chemoradiotherapy and selective surgery during the same time interval. The former patients underwent esophagectomy before consultation at the Vancouver Island Cancer Centre.

\section{PATIENTS AND METHODS}

Patients registered at the Vancouver Island Cancer Centre after undergoing esophagectomy with curative intent for invasive esophageal cancer between January 1993 and January 1998 were identified. Regional hospital records were reviewed to confirm that the referred esophagectomy patients represented $100 \%$ of treated patients. Patients treated with primary chemoradiotherapy during the same time period were also identified. The medical records of all patients who underwent surgery (with or without chemoradiotherapy) were abstracted to include the name of the operating surgeon, dates of hospitalization, procedure undertaken, operating room time, transfusions, intensive care unit time, anastomotic leaks, postoperative antibiotic prescription, hypotension, small bowel obstruction, cardiovascular events, infections, venous thrombosis, fistulas, number of thoracostomy tubes, pre- and postoperative degree of dysphagia, and need for re-exploration. Charts were reviewed in early 2000, and the last follow-up was in May 2000. All staging was 'clinical' using the International Union Against Cancer system:

- Stage I - T1NOMO

- Stage II - T2NOMO

- Stage III - any T3, any N1M0

Endoscopic examination and computed tomography (CT) scan were the primary staging techniques. Endoscopic ultrasound was not used. 


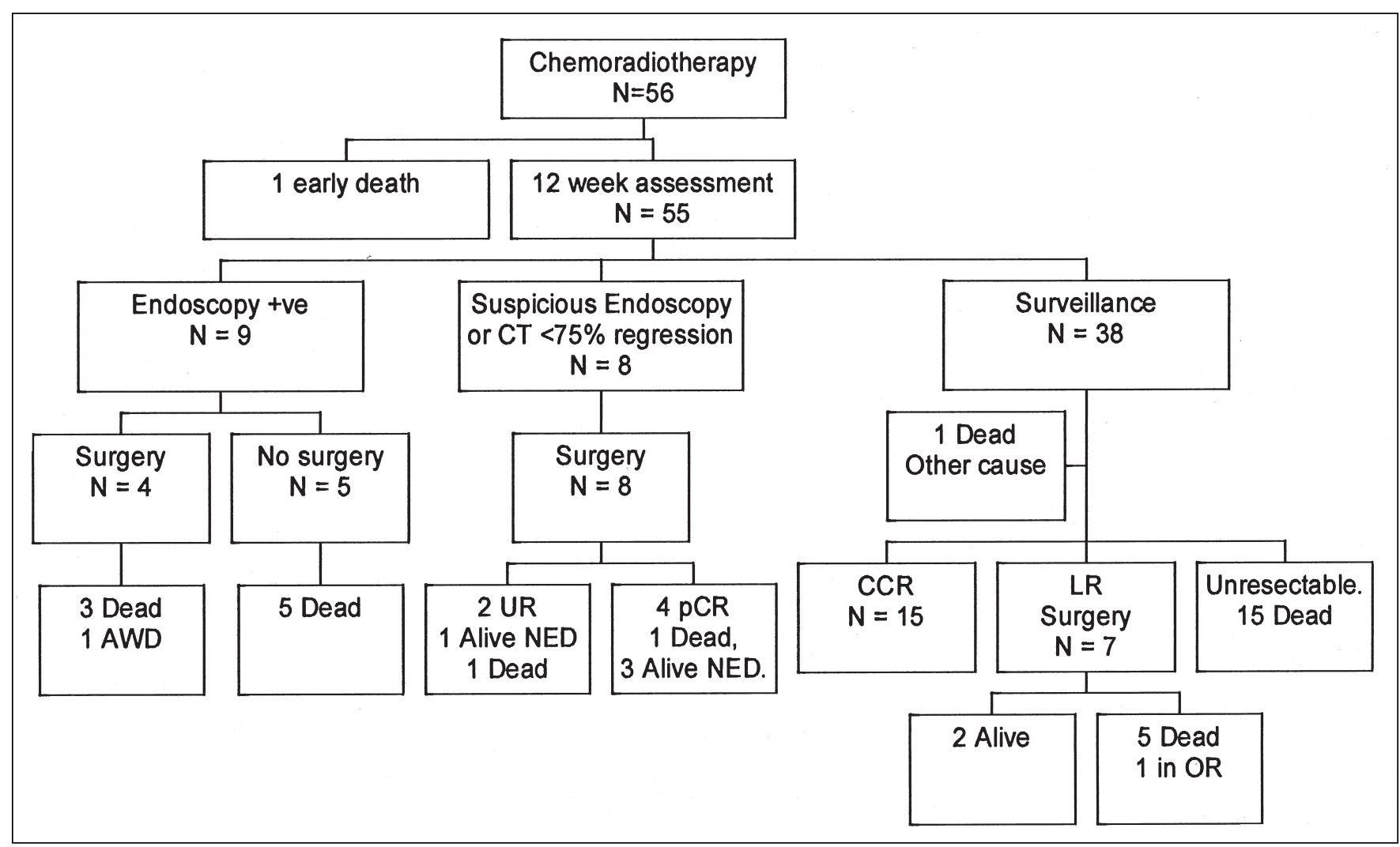

Figure 1) Treatment schema and patient disposition after undergoing chemoradiotherapy and selective surgery. AWD Alive with disease; CCR Continuous complete remission; CT Computed tomography; LR Local recurrence; NED No evidence of disease; OR Operating room; pCR Pathological complete remission; UR Unresectable; +ve Positive

Full details of the eligibility and treatment plan for chemoradiotherapy and selective surgery have been reported (7). In summary, these were:

- invasive carcinoma (any clinical $\mathrm{T}$ or $\mathrm{N}$ status, M zero);

- disease encompassable in radical radiation therapy (RT) ports;

- no prior surgical excision, disease not crossing the gastroesophageal junction, Eastern Cooperative Oncology Group performance status less than 2; and

- medically fit for curative chemoradiotherapy, but not necessarily candidates for surgery at the time of diagnosis.

Three cycles of cisplatin/fluorouracil chemotherapy were planned for weeks 0, 3 and 6, with RT 50 Gy in 25 fractions commencing at week 3. Follow-up endoscopic examination and CT scan were planned four weeks after completing RT. Selective surgery was recommended to patients with pathologically positive or suspicious endoscopy, less than 75\% regression on CT scan or resectable local relapse (Figure 1). Patients with negative biopsies and greater than 75\% regression on computed axial tomography scan remained under endoscopic surveillance at intervals of three and six months in the first and second years of follow-up, respectively. Local relapse was defined as histologically confirmed tumour recurrence at the primary site, by endoscopic examination.

For patients who underwent chemoradiotherapy, toxicity and survival data were collected prospectively using dBaseIV (Ashton-Tate Corporation, DBaseIV Software, USA) and later Microsoft Excel (Microsoft, USA). Surgical complications and survival were recorded retrospectively using the common toxicity grades of the National Cancer Institute of Canada Clinical Trials Group. Cause-specific survival analyses were undertaken by the Kaplan-Meier method using SPSS for Windows (Version 7.5 , SPSS Inc, USA). Survival curves were compared with the log rank test (9). Differences between proportions were analyzed with $\chi^{2}$ or Fisher's exact test. Two patients who underwent exploration but were found to have unresectable disease after chemoradiotherapy were included in the survival analysis among patients who did not have curative surgery. One patient who underwent chemoradiotherapy sustained a fatal intraoperative hemorrhage and was included in the toxicity and survival analyses of patients who underwent selective surgery. One patient underwent selective surgery after completion of the chart review process, and his hospitalization details were not included.

\section{RESULTS}

Between 1993 and 1998, 75 patients received curative treatment for esophageal cancer. Nineteen patients under- 
TABLE 1

Patient characteristics and frequency of complications

\begin{tabular}{|c|c|c|c|c|}
\hline & $\begin{array}{c}\text { Group 1: } \\
\text { All chemoradiotherapy } \\
\text { lus selective surgery }(n=56)\end{array}$ & $\begin{array}{c}\text { Group 2: } \\
\text { Selective } \\
\text { surgery }(n=16)\end{array}$ & $\begin{array}{c}\text { Group 3: } \\
\text { Surgery } \\
\text { alone }(n=19)\end{array}$ & $\mathbf{P}$ \\
\hline Age (years) & 66 (range 44 to 78 ) & 64 & 67 (range 41 to 77 ) & Stage/treatment \\
\hline Number with stage 1 disease & 4 & 0 & 5 & 0.08 (2 versus 3$)$ \\
\hline Number with stage 2 disease & 28 & 10 & 8 & 0.08 ( 1 versus 3$)$ \\
\hline Number with stage 3 disease & 24 & 6 & 6 & \\
\hline $\begin{array}{l}\text { Number with primary disease involving } \\
\text { the distal } 10 \mathrm{~cm} \text { of the esophagus (\%) }\end{array}$ & $31(55)$ & $15(94)$ & $17(89)$ & $0.02(1$ versus 3$)$ \\
\hline Number with adenocarcinoma (\%) & $24(43)$ & $10(63)$ & $14(74)$ & $\begin{array}{l}0.16(1 \text { versus } 3) \\
0.72(2 \text { versus } 3)\end{array}$ \\
\hline Median operating room time $(\mathrm{h})$ & & 3.3 & 2.5 & 0.3 \\
\hline $\begin{array}{l}\text { Median number of operating room } \\
\text { red blood cell transfusions }\end{array}$ & & 1.7 & 2.3 & NS \\
\hline \multicolumn{2}{|l|}{ Median time in intensive care unit (days) } & 2 & 3 & 0.6 \\
\hline \multicolumn{2}{|l|}{ Postoperative hospital stay (days) } & 14 & 13 & 0.9 \\
\hline \multicolumn{2}{|l|}{ Number with two chest tubes } & 10 & 8 & 0.31 \\
\hline \multicolumn{2}{|l|}{ Number with anastomotic leaks } & 1 & 3 & 0.61 \\
\hline \multicolumn{2}{|l|}{ Number with fistulas } & 0 & 2 & 0.49 \\
\hline \multicolumn{2}{|l|}{ Number with grade 3 or higher hypotension } & 3 & 5 & 0.7 \\
\hline \multicolumn{2}{|l|}{ Number requiring postoperative antibiotics } & 10 & 11 & 1.0 \\
\hline \multicolumn{2}{|l|}{ Number with small bowel obstruction } & 0 & 2 & 0.49 \\
\hline
\end{tabular}

NS Not significant

went esophagectomy alone and 56 patients underwent primary chemoradiotherapy - of whom 16 had selective surgery. Esophagectomy was performed by 12 surgeons, two of whom performed 17 (49\%) procedures. Three esophagectomies were performed in other tertiary centres by two thoracic surgeons. The remaining 15 esophagectomies were performed by eight surgeons. The esophagectomy approaches used were transhiatal $(\mathrm{n}=22)$, transthoracic $(n=4)$ and esophagogastrectomy $(n=9)$. Characteristics and complication rates for the three patient groups - esophagectomy alone, all chemoradiotherapy and selective surgery are shown in Table 1. There was a trend toward higher stage of disease among patients who underwent chemoradiotherapy plus selective surgery $(\mathrm{P}=0.08)$. Postoperative degree of dysphagia was the same or better in $63 \%$ of patients who underwent esophagectomy alone and in $57 \%$ of patients who underwent selective surgery $(\mathrm{P}=1.0)$. Among patients who underwent chemoradiotherapy plus selective surgery, 12 (seven with adenocarcinoma and five with squamous cell carcinoma) underwent surgery after the first postchemoradiotherapy endoscopy, and seven (four with adenocarcinoma, two with squamous cell carcinoma and one with uncertain histology) underwent surgery because of relapse. Two patients in the early surgery group were found to have unresectable disease, and one patient with local recurrence after undergoing chemoradiotherapy died from intraoperative hemorrhage, leaving 16 who underwent esophagectomy. The disposition of patients according to response assessment on completion of chemoradiotherapy is summarized in Figure 1. Among the patients who underwent chemoradiotherapy and esophagectomy $(n=16)$, there were nine adenocarcinomas, compared with 24 adenocarcinomas in the whole population of chemotherapy patients $(n=56)$ $(\mathrm{P}=0.51)$. Among the patients who underwent chemoradiotherapy plus selective surgery, 11 underwent transhiatal esophagectomies (seven are currently alive), two underwent transthoracic esophagectomies (both are currently alive) and three underwent esophagogastrectomies (all have died).

The median follow-up time for all patients was 12.9 months, and was 22.6 months for those who did not die from esophageal cancer. All but one of the deaths due to esophageal cancer $(n=48)$ occurred within 31 months of diagnosis. One-half of the deaths occurred within the first year, and 35\% occurred in the second year. One death at 54 months was from bone metastases, without histological confirmation, but was presumed to have been secondary to esophageal cancer. Failure rates in the patients who underwent chemoradiotherapy plus selective surgery were $41 \%$ (local with or without distant) and 39\% (distant with or without local). Failure analysis was not available for 


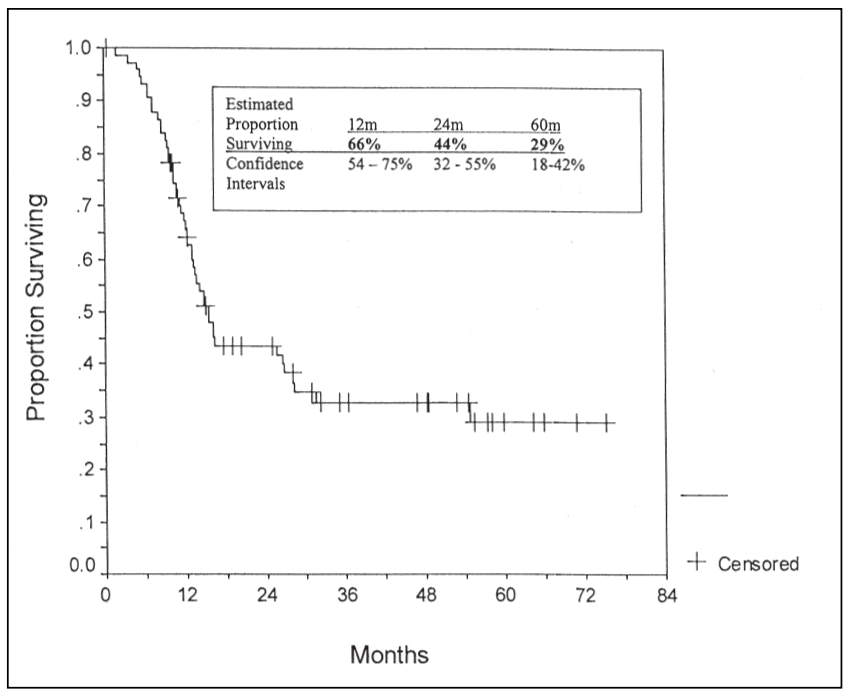

Figure 2) Cause-specific survival analysis for all patients, estimated proportion surviving and confidence intervals at different time points

patients who underwent esophagectomy alone. The median survival for all patients was 15.4 months, with $29 \%$ surviving five years (Figure 2). For patients who underwent esophagectomy alone and those who underwent chemoradiotherapy plus selective surgery, the median survival times were 12.9 and 16.4 months, respectively ( $\log$ rank $\mathrm{P}=0.08)$, and the three-year survival rates were $21 \%$ and $37 \%$, respectively (Figure 3). Seventeen of 25 patients who underwent chemoradiotherapy and survived more than two years have not required selective surgery.

Survival analysis was undertaken to examine the following factors: sex, age at diagnosis, $\mathrm{T}$ status, $\mathrm{N}$ status, histology, primary tumour location, surgical procedure, chemoradiotherapy plus selective surgery, or esophagectomy alone. No single prognostic factor for survival was statistically significant, although there were trends toward significance in univariate analyses for sex $(\mathrm{P}=0.07)$, treatments (chemoradiotherapy plus selective surgery, or esophagectomy alone) $(\mathrm{P}=0.08)$ and type of surgery (no surgery versus different types of operations), with esophagogastrectomy being favoured $(P=0.06)$. However, none of these factors retained significance in multivariate analyses. Among patients who underwent chemoradiotherapy and selective surgery, the five-year survival rates were $46 \%$ in those with squamous cell carcinoma and $27 \%$ in those with adenocarcinoma $(\mathrm{P}=0.25)$. The only significant determinant of survival was endoscopic response after chemoradiotherapy (negative versus positive biopsy, $\mathrm{P}<0.0001$ ).

\section{DISCUSSION}

We report the outcomes for all patients treated with curative intent for esophageal cancer in the Vancouver Island Cancer Centre from 1993 to 1998. Cause-specific survival for all patients is consistent with historical experience (10). A similar type of outcome analysis of patients who underwent chemoradiotherapy $(n=82)$ and those who underwent

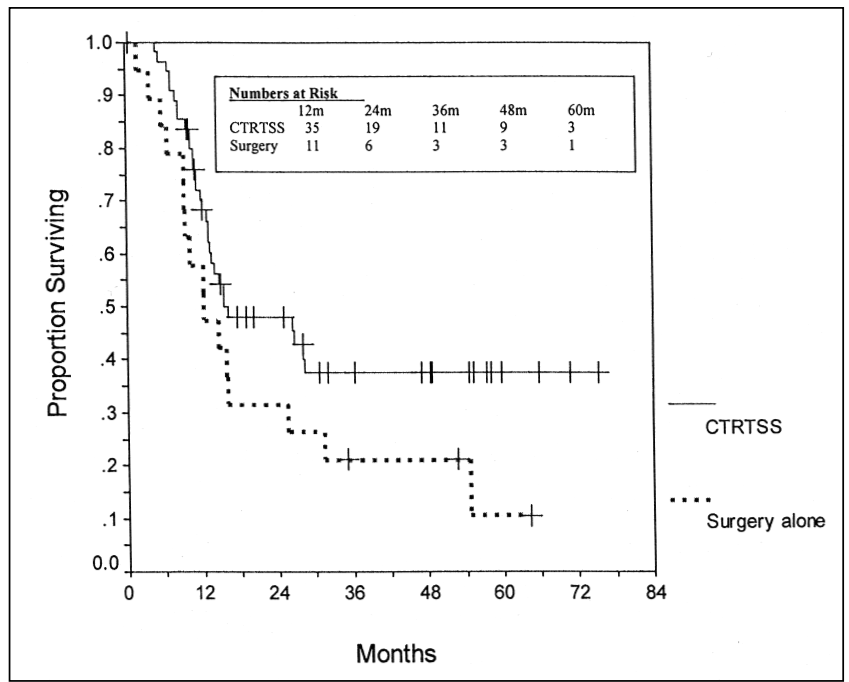

Figure 3) Cause-specific survival analysis according to patient groups: chemoradiotherapy and selective surgery (CTRTSS) or surgery alone

concurrent esophagectomy only $(\mathrm{n}=81)$ has been reported from the University of Calgary, Alberta (11). Although in that study, as in our study, patients who underwent chemoradiotherapy had a higher stage of disease than those who underwent esophagectomy only, the five-year local recurrence rates were comparable (59\% versus 51\%). The distant metastasis rates were lower in those who underwent chemoradiotherapy, and the five-year survival rates were equivalent (25\% versus $23 \%)$. Stage was a highly significant prognostic factor, but histology was not. Stage distributions for the Calgary chemoradiotherapy series $(n=9$, $\mathrm{n}=48$ and $\mathrm{n}=25$ in stages I, II and III, respectively) and those for the present series were not significantly different. The estimated five-year disease-specific rate of survival in our series for all patients who underwent chemoradiotherapy was $37 \%$ compared with the $25 \%$ overall rate of survival in the Calgary series. These cure rates contrast with those reported from Saskatchewan of 306 consecutive patients with esophageal cancer seen at the Saskatoon Cancer Centre from 1970 to 1992 , in which 82\% of patients died of disease, $11 \%$ died of other causes and none were cured (12).

Outcomes after the primary surgical management of esophageal cancer have been reviewed $(6,13)$. The two most popular surgical procedures - transhiatal and transthoracic esophagectomy - accounted for $74 \%$ of operations in the present series. Historically, there has not been a clear survival benefit from one or the other type of surgery $(14,15)$. A perioperative mortality rate of $3 \%$ and surgical morbidity rates in the present series compare favourably with those of other experiences. In a 1990 review of surgery for esophageal cancer (2), the average hospital mortality rate was $13 \%$, but it was noted that operative mortality had decreased by more than $50 \%$ during the 1980 s. The frequency of nonfatal complications from transhiatal esophagectomy (16) and transthoracic esophagectomy (17) can 
also be substantial. For transhiatal esophagectomy, major complication rates are $12 \%$ respiratory, $18 \%$ cardiac, $24 \%$ anastomotic leak and 3\% mediastinal hemorrhage (16), with which complication rates in the present series are consistent.

Comparison of survival among patients in the present series undergoing transhiatal and transthoracic esophagectomy, and esophagogastrectomy is limited by small numbers and the fact that 16 operations were performed in patients with persistent or recurrent disease after chemoradiotherapy, putting them in a potentially poorer prognostic group. However, there is a salvage rate from selective surgery in patients with local relapse but not among those with endoscopically positive disease after chemoradiotherapy. There have been conflicting reports of the prognostic significance of persisting disease after chemoradiotherapy. Five-year survival has been correlated with the presence of either microor macroscopic disease in the esophagectomy specimen; patients with only microscopic disease have survival rates similar to those without evidence of cancer (18), suggesting that esophagectomy is beneficial in the former group. However, no patients with gross disease in esophagectomy specimens survived five years. The only significant factor predicting disease-free survival in multivariate analysis was tumour regression grade (18). Other series have reached the opposite conclusion, ie, that pathological complete response in the esophagectomy specimen was not necessarily a prognostic factor for survival after CT and/or RT $(19,20)$. These differences in outcomes after chemoradiotherapy and planned surgery may reflect differing CT and/or RT regimens and patient populations.

Several recent phase III trials are available for the contemporary comparison of operative mortality between patients who undergo preoperative chemoradiotherapy and those who undergo esophagectomy alone. In a trial of patients undergoing chemoradiotherapy and esophagectomy for adenocarcinoma (4), there were four $(8 \%)$ deaths among 51 patients undergoing chemoradiotherapy, and two deaths among 55 patients undergoing esophagectomy alone. The difference in death rates was not significant. The incidence of postoperative complications in this trial was $48 \%$ for those undergoing chemoradiotherapy only and $58 \%$ for those undergoing esophagectomy only. However, complication grades were not reported. In a study of chemoradiotherapy and esophagectomy in patients with squamous cell carcinoma (3), postoperative mortality was significantly greater in patients who underwent chemoradiotherapy than in those who underwent esophagectomy alone $(12 \%$ versus $4 \%)$. This difference was due to more frequent respiratory insufficiency, mediastinal infection and sepsis. There was also a trend toward higher complication rates in patients who underwent chemoradiotherapy (26.3\% versus $32.6 \%$ [esophagectomy versus chemoradiotherapy plus esophagectomy]), mostly due to pneumonia, infections and anastomotic leakage. In another study of 104 patients with squamous cell cancer, postoperative mortality was $8 \%$, both in those who underwent chemoradiotherapy and in those who underwent chemoradiotherapy and esophagectomy (21).

Although cure is the ultimate goal, relief of dysphagia is often the dominant immediate concern in the management of esophageal cancer. We found that relief of dysphagia after immediate esophagectomy was equivalent to that after primary chemoradiotherapy and selective surgery. After esophagectomy alone, the majority of patients are able to swallow within two weeks of operation (22). The effects of chemoradiotherapy alone on swallowing function have been reported to show initial improvement in $88 \%$ of patients and a median time to improvement of two weeks (23). Improvements in dysphagia were unrelated to histological type, but those with distal tumours had both earlier and more frequent initial improvement than patients with tumours in the upper two-thirds of the esophagus (95\% versus 79\%) (23). All patients treated with curative chemoradiotherapy who survived disease-free for longer than one year were able to eat soft or solid foods and had a benign stricture rate of only $12 \%$.

In the present series, the majority of long term survivors did not require esophagectomy (24). Until recently, organ preservation has generally been limited to patients who are unfit for surgery. The possibility of organ preservation has been explored by several groups, but no phase III trials examining the role of esophagectomy after definitive chemoradiotherapy have been undertaken. Favourable results with chemoradiotherapy compared with esophagectomy in patients with T1 and T2 esophageal cancer (25), have supported the concept that chemoradiotherapy may be an alternative to esophagectomy $(26,27)$. Integration of selective esophagectomy into primary chemoradiotherapy has been reported using several criteria for esophagectomy $(7,25)$. In a report of 66 patients treated with either esophagectomy alone, or chemoradiotherapy and surgery for those with less than $75 \%$ regression on CT scan, four of 36 patients who underwent chemoradiotherapy underwent esophagectomy. In patients with T1 and T2 cancers, organ conservation rates of $92 \%$ and $58 \%$, and three-year survival rates of $83 \%$ and $51 \%$, respectively, have been reported (25). Incorporation of combination chemotherapy before simultaneous chemoradiotherapy has also been reported in patients with squamous cell carcinoma $(26,27)$, with fiveyear survival rates of $26.7 \%$ and $35 \%$, respectively. None of the 65 patients in the former study (26) underwent esophagectomy, and only three of 55 patients in the latter study (27) underwent esophagectomy, all of whom had pathologically complete remission. Our experience of a $46 \%$ five-year survival rate in patients with squamous cell cancer suggests that planned selective surgery may contribute to an apparently superior outcome. However, this would require confirmation in a prospective, randomized trial.

Major factors in determining surgical complication rates are hospital and physician volume, and specialization. Thirty-day mortality rates after esophagectomy vary from $17.3 \%$ for institutions undertaking one to five cases per 
annum to $3.4 \%$ for those undertaking more than 11 cases per annum (28). In another study of hospital mortality in patients with esophageal cancer (29), the average mortality was $4.8 \%$ when more than 30 esophagectomy procedures per annum were undertaken, compared with $16 \%$ if fewer than 30 were performed per annum. In the present series, 12 surgeons undertook 35 esophagectomies over a sevenyear period, and two surgeons performed $50 \%$ of the procedures. Over time, however, there has been an increasing acceptance that esophagectomy is a procedure that should be performed by suitably experienced surgeons. Locally, this has evolved into triage of new esophageal cancer patients at the Vancouver Island Cancer Centre to optimize and integrate multidisciplinary care.

Delays in esophagectomy after curative chemoradiotherapy could theoretically be disadvantageous. Chemoradiotherapy-resistant cancers might be curable surgically. The corollary is that some surgically incurable patients may be curable with chemoradiotherapy. From knowledge of tumour doubling times (30), however, chemoradiotherapy patients who develop distant metastases within one year of diagnosis are likely to be surgically incurable. A strategy analogous to that used for other chemoradiotherapy-sensitive cancers (31) could reasonably be used, ie, reserving surgery for patients not already cured by chemoradiotherapy. Invasive staging with thoracoscopy and laparoscopy may help to identify some patients with occult metastases, which would preclude cure with either esophagectomy or chemoradiotherapy, or alter RT treatment plans (32). Identification of molecular markers of de novo chemoradiotherapy resistance could also be helpful in planning treat-

\section{REFERENCES}

1. CancerNet. <http://www.cancer.gov/cancer_information/ doc_pdq.aspx?version=1\&viewid=da2ae45a-2816-49b8-8d34eda121c0a68f .> (Version current at February 15, 2002)

2. Muller JM, Erasmi H, Stelzner M, et al. Surgical therapy of esophageal carcinoma. Br J Surg 1990;77:845-57.

3. Bosset JF, Gignoux M, Triboulet JP, et al. Chemoradiotherapy followed by surgery compared with surgery alone in squamous-cell cancer of the esophagus. N Engl J Med 1997;337:161-7.

4. Walsh TN, Noonan N, Hollywood D, et al. A comparison of multimodal therapy and surgery for esophageal adenocarcinoma. N Engl J Med 1996;335:462-7.

5. Urba S, Orringer M, Turrisi A, et al. Randomised trial of preoperative chemoradiation versus surgery alone in patients with locoregional esophageal cancer. J Clin Oncol 2001;19:305-13.

6. Reed C. Surgical management of esophageal carcinoma. Oncologist 1999;4:95-105.

7. Wilson KS, Lim J. Primary chemo-radiotherapy and selective esophagectomy for esophageal cancer: goal of cure with organ preservation. Radiother Oncol 2000;54:129-34.

8. Wilson KS, Lim JT, Wilson AG, Dewar GJ. Chemo-radiotherapy and selective surgery or surgery alone in radical treatment of esophageal cancer (EC): is one strategy superior? Proc Am Soc Clin Oncol 2000;19:293. (Abst 1145)

9. Peto R, Pike MC, Armitage P, et al. Design and analysis of randomised clinical trials requiring prolonged observation of each patient. II. Analysis and examples. Br J Cancer 1977;35:1-39.

10. Roth JA, Putnam JB, Rich TA, et al. Cancer of the esophagus. In: DeVita VT, Hellman S, Rosenberg SA, eds. Cancer: Principles and Practice of Oncology. Philadelphia: Lippincott-Raven, 1997.

11. Chan A, Wong A. Is combined chemotherapy and radiation therapy equally effective as surgical resection in localised esophageal carcinoma? Int J Radiat Oncol Biol Phys 1999;45:265-70. ment $(33,34)$. Positron emission tomographic scanning is also under investigation for the assessment of response after chemoradiotherapy and the presence of distant metastases $(35,36)$. Future trials of surgery after chemoradiotherapy should consider invasive staging and, where available, positron emission tomographic scanning.

\section{CONCLUSIONS}

Within the limits of sample size and selection bias considerations, the surgical complication and disease-specific survival rates after primary chemoradiotherapy and selective surgery appear to be at least comparable with those seen after esophagectomy alone. A prospective, randomized trial is necessary for the definitive evaluation of chemoradiotherapy and selective surgery.

\section{ADDENDUM}

In subsequent analysis (February 2002) of chemoradiotherapy in patients who underwent selective surgery $(n=56)$, the median survival was 26.4 months (95\% CI 11.7 to 41.1 months), the five-year survival proportion was 37\% (95\% CI 22 to 50\%), and the significant independent prognostic factors were $\mathrm{N}$ status and endoscopic response $(\mathrm{P}=0.03$ and $\mathrm{P}<0.0001$, respectively).

ACKNOWLEDGEMENTS: This article was published in abstract form at the Annual Meeting of the American Society of Clinical Oncology, New Orleans, May 19 to 23, 2000. We gratefully acknowledge the contributions of our colleagues in the care of the patients herein reported.
12. Moyana TN, Janoski M. Recent trends in the epidemiology of esophageal cancer. Comparison of epidermoid and adenocarcinomas. Ann Clin Lab Sci 1996;26:480-6.

13. Teng S, Karl R. Surgical approaches to esophageal cancer. Cancer Control 1999;6:36-42.

14. Goldminc M, Maddern G, Le Prise E, et al. Oesophagectomy by transhiatal approach or thoracotomy: a prospective randomised trial. Br J Surg 1993;80:367-70.

15. Chu KM, Law SY, Fok M, et al. A prospective randomised comparison of transhiatal and transthoracic resection for lower third esophageal carcinoma. Am J Surg 1997;174:320-4.

16. Gandhi SK, Naunheim KS. Complications of transhiatal esophagectomy. Chest Surg Clin N Am 1997;7:601-12.

17. Bains MS. Complications of abdominal right thoracic (Ivor Lewis) esophagectomy. Chest Surg Clin N Am 1997;7:587-98.

18. Mandard AM, Dalibard F, Mandard JC, et al. Pathologic assessment of tumour regression after preoperative chemoradiotherapy of esophageal carcinoma: clinicopathologic correlations. Cancer 1994;73:2680-6.

19. Jones DR, Detterbeck FC, Egan TM, et al. Induction chemoradiotherapy followed by esophagectomy in patients with carcinoma of the esophagus. Ann Thorac Surg 1997;64:185-91.

20. Kane JM III, Shears LL, Ribeiro U, et al. Is esophagectomy following up-front chemoradiotherapy safe and necessary? Arch Surg 1997;132:481-5.

21. Le Prise E, Etienne PL, Meunier B, et al. A randomised study of chemotherapy, radiation therapy, and surgery versus surgery for localised squamous cell carcinoma of the esophagus. Cancer 1994;73:1779-84.

22. Ellis F, Gibb S, Watkins E. Overview of the current management of carcinoma of the esophagus and cardia. Can J Surg 1985;28:493-6. 
23. Coia LR, Soffen EM, Schultheiss TE, et al. Swallowing function in patients with esophageal cancer treated with concurrent radiation and chemotherapy. Cancer 1993;71:281-6.

24. Wilson KS, Lim JT. Chemoradiotherapy of esophageal cancer. Int J Radiat Oncol Biol Phys 2000;47:539.

25. Murakami M, Kuroda Y, Nakajima T, et al. Comparison between chemoradiation protocol intended for organ preservation and conventional surgery for clinical T1-T2 esophageal carcinoma. Int J Radiat Biol Phys 1999;45:277-84.

26. Zenone T, Romestaing P, Lambert R, et al. Curative nonsurgical combined treatment of squamous cell carcinoma of the esophagus. Eur J Cancer 1992;28A:1380-6.

27. Roca E, Pennella E, Sardi M, et al. Combined intensive chemoradiotherapy for organ preservation in patients with resectable and non-resectable esophageal cancer. Eur J Cancer 1996;32A:429-32.

28. Begg CB, Cramer LD, Hoskins WJ, et al. Impact of hospital volumes on operative mortality for major cancer surgery. JAMA 1998;280:1747-51.

29. Patti MG, Corvera CU, Glasgow RE, et al. A hospital's annual rate of esophagectomy influences the operative mortality rate. J Gastrointest Surg 1998;2:186-92.

30. Tannock IF. Cell proliferation. In: Tannock IF, Hill RP, eds. The Basic Science of Oncology. New York: McGraw-Hill, 1992.

31. Tobias JS, Ball D. Synchronous chemoradiation for squamous carcinomas. Br Med J 2001;322:876-8.

32. Krasna MJ, Mao YS, Sonett J, Gamliel Z. The role of thoracoscopic staging of esophageal cancer patients. Eur J Cardiothorac Surg 1999;16(Suppl 1):S31-3.

33. Lam AKY. Molecular biology of esophageal squamous cell carcinoma. Crit Rev Oncol Hematol 2000;33:71-90.

34. Ribeiro U, Finkelstein SD, Safatle-Ribeiro AV, et al. P53 sequence analysis predicts treatment response and outcome of patients with esophageal carcinoma. Cancer 1998;83:7-18.

35. Couper GW, McAteer D, Wallis F, et al. Detection of response to chemotherapy using positron emission tomography in patients with esophageal and gastric cancer. Br J Surg 1998;85:1403-6.

36. Luketich JD, Friedman DM, Weigel TL, et al. Evaluation of distant metastases in esophageal cancer: 100 consecutive positron emission tomography scans. Ann Thorac Surg 1999;68:1133-6. 


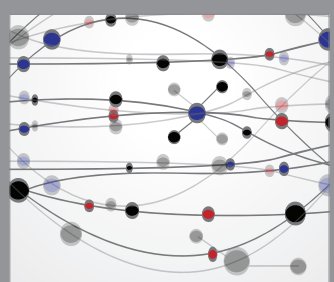

The Scientific World Journal
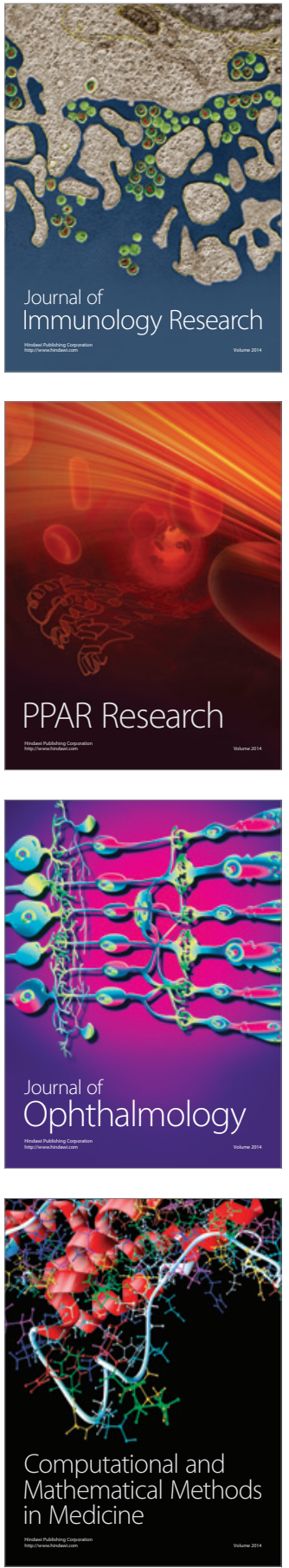

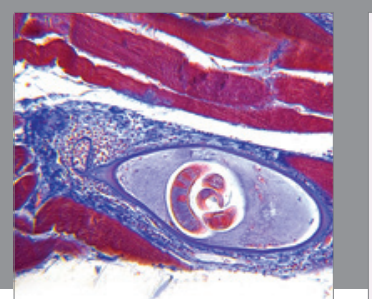

Gastroenterology Research and Practice

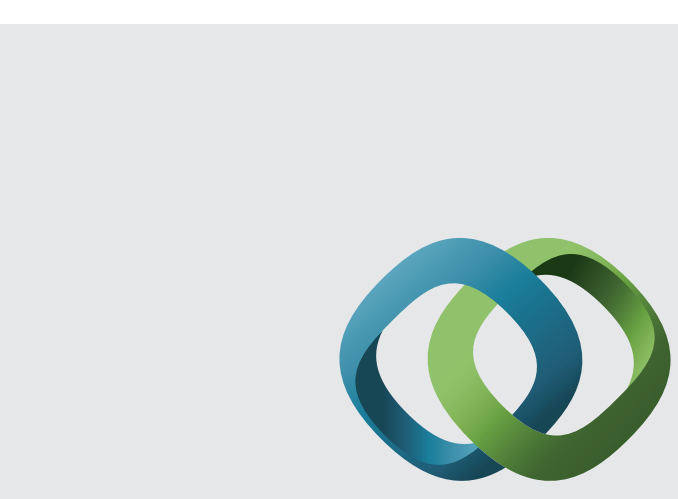

\section{Hindawi}

Submit your manuscripts at

http://www.hindawi.com
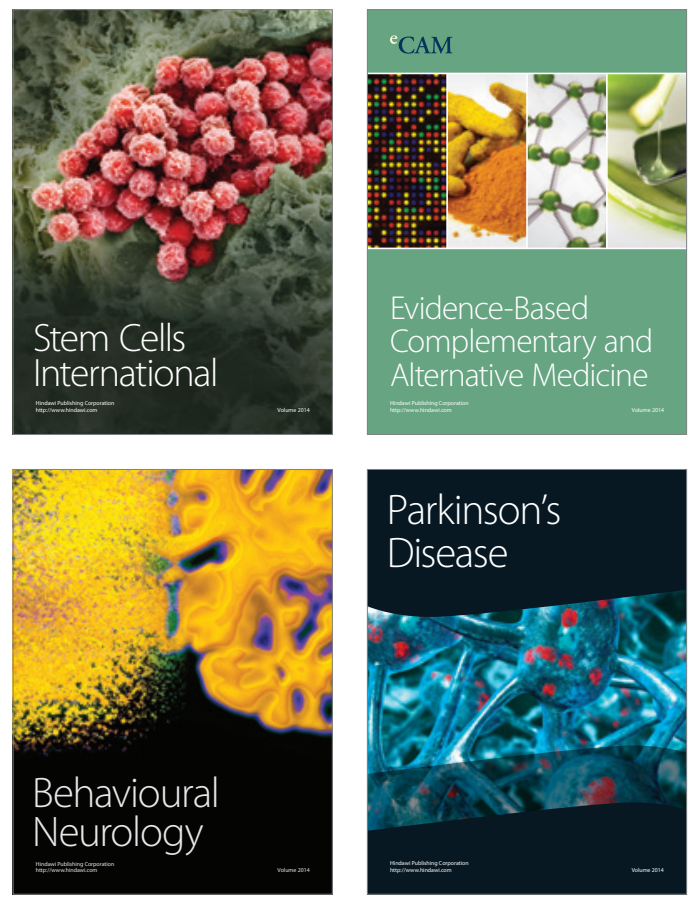
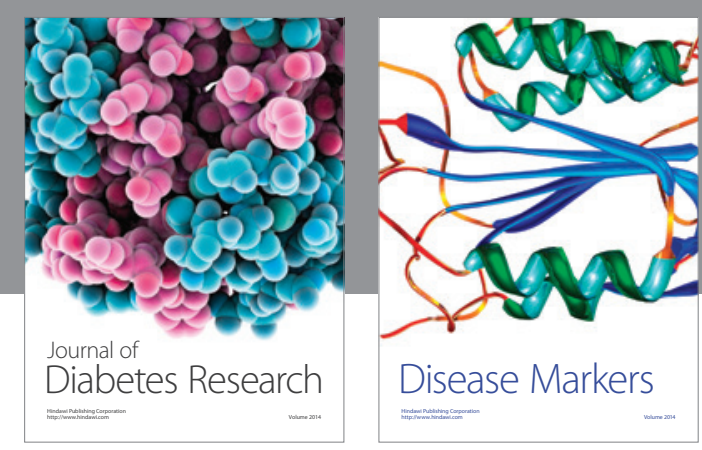

Disease Markers
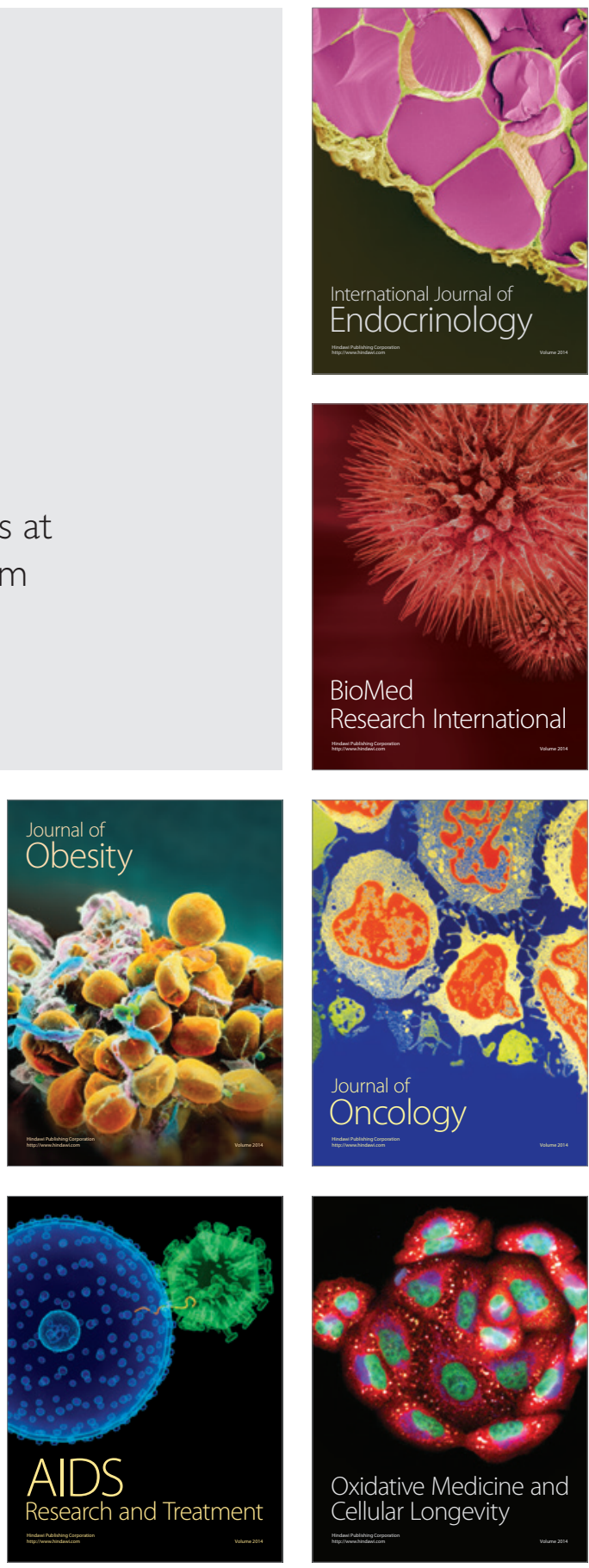